\title{
Discrimination, Attribution, and Racial Group Identification: Implications for Psychological Distress Among Black Americans in the National Survey of American Life (2001-2003)
}

\author{
David H. Chae \\ Emory University
}

\author{
Karen D. Lincoln \\ University of Southern California
}

\author{
James S. Jackson \\ University of Michigan
}

\begin{abstract}
There is increasing evidence that experiencing discrimination may contribute to poor mental health among Black Americans. However, few studies have distinguished between discrimination attributed to race versus other forms of discrimination or have compared differences in their psychological implications. Using nationally representative data on 5,191 Black Americans in the National Survey of American Life (NSAL; 2001-2003), this study examined serious psychological distress (SPD) in relation to discrimination attributed to racial versus nonracial causes and also investigated whether racial group identification may be a buffer. We found that discrimination was associated with greater odds of SPD, regardless of attribution. Racial attributions were associated with higher odds of SPD compared with attributions to nonracial causes for each level of discrimination. High racial group identification buffered the negative effect of moderate levels of both racially and nonracially attributed discrimination. Our results provide evidence for the negative influence of discrimination on SPD among Black Americans and indicate that high racial group identification may somewhat mitigate their negative mental health effects. Our study suggests that discrimination and racial group identification should be addressed to protect against psychological distress among Black Americans.
\end{abstract}

B lack Americans continue to face contemporary forms of overt and subtle discrimination in a number of domains, including housing, employment, medical care, the criminal justice system, and in public places, despite the existence of protective legislation. Discrimination is also experienced routinely, including instances of being treated with less courtesy or respect in everyday interactions (Krieger, 2000; Williams, Neighbors, \& Jackson, 2003). Moreover, a growing body of research suggests that these experiences may have negative mental health consequences (Bhui et al., 2005; Gee, Ryan, Laflamme, \& Holt, 2006; Romero \& Roberts, 2003; Schmitt, Branscombe, \& Postmes, 2003; Williams \& Williams-Morris, 2000; Williams et al., 2003). Studies have consistently shown that greater selfreported experiences of discrimination are associated with poorer mental health outcomes among minority groups (Bro-

Correspondence concerning this article should be addressed to David H. Chae, Department of Behavioral Sciences and Health Education, Emory University, Rollins School of Public Health, 1518 Clifton Rd. NE, Room 512, Atlanta, GA 30322. Electronic mail may be sent to david.chae@emory.edu. man, Mavaddat, \& Hsu, 2000; Díaz, Ayala, Bein, Henne, \& Marin, 2001; Finch, Kolody, \& Vega, 2000; Gee, Spencer, Chen, Yip, \& Takeuchi, 2007; Yoshikawa, Wilson, Chae, \& Cheng, 2004). Studies specifically conducted among Black Americans have also found positive associations between discrimination and poor mental health outcomes, including depression, anxiety, and global psychological distress (Branscombe, Schmitt, \& Harvey, 1999; Broman et al., 2000; Jackson et al., 1996; Klonoff, Landrine, \& Ullman, 1999). For example, a recent longitudinal study found that changes in self-reported discrimination predicted differences in depression over time among Black women (Schulz et al., 2006).

Various mechanisms may be involved linking discrimination and psychological distress among Black Americans, including indirect as well as direct effects on mental health. For example, institutional forms of discrimination that segregate Black Americans into worse structural conditions and neighborhoods characterized by fewer psychosocial resources may lead to worse mental health (Jargowsky, 1997; Williams \& Collins, 2001). Furthermore, discrimination experienced in education and employment may lead to lower levels of socioeconomic attainment that can adversely impact psychological well-being (Neighbors, 
Jackson, Broman, \& Thompson, 1996). Other models suggest that interpersonal forms of discrimination may have direct effects on psychological well-being via the internalization of negative racial group attitudes, which can lead to poorer selfevaluation and worse mental health (Clark, Anderson, Clark, \& Williams, 1999; Meyer, 2003; Williams \& Williams-Morris, 2000). For example, social identity theory suggests that individuals may derive poor self-concept from negative social values attached to devalued groups, which can adversely impact selfesteem and mental health (Tajfel \& Turner, 1986).

Belying these frameworks are epidemiologic studies suggesting that Black Americans have similar, if not lower, levels of mental health problems compared with White people, even though facing worse residential and socioeconomic conditions and reporting higher levels of discrimination. For example, recent national surveillance data indicated that non-Hispanic White people have the highest prevalence of lifetime major depressive disorder $(17.9 \%)$, followed by Caribbean Black people (12.9\%) and African Americans (10.4\%; Williams et al., 2007). Earlier large scale studies have also reported that Black Americans have either an equal or lower prevalence of psychiatric disorders compared with non-Hispanic White people (Blazer, Kessler, McGonagle, \& Swartz, 2004; Breslau, Kendler, Su, Gaxiola-Aguilar, \& Kessler, 2005; Kessler, Berglund et al., 2003; Kessler et al., 1994). Findings from these studies suggest additional pathways that may be involved in the epidemiology of psychological problems among Black Americans.

\section{Discrimination, Attribution, and Racial Group Identification}

The relationship between experiences of discrimination and mental health may be contingent on attributions and responses to such experiences. For example, some studies suggest that interpreting negative experiences as instances of racial discrimination may be self-protective (e.g., Crocker \& Major, 1989; Major, Kaiser, \& McCoy, 2003; Weiner, 1985). Accordingly, attributions to group-based discrimination may serve to minimize personal attributes as causes of negative experiences, thereby serving to protect self-esteem (Crocker \& Major, 1989). On the other hand, other researchers have suggested that attributing negative experiences to racial discrimination may in fact have more detrimental mental health consequences (Schmitt \& Branscombe, 2002). Because attributing negative experiences to race entails a threat to a stable and salient social identity, such attributions may in fact have more negative mental health consequences. Evidence for this perspective was reported in a study of Black university students, which found that making attributions to racial discrimination in response to a hypothetical negative situation was associated with lower self-esteem and poorer affect compared with those who made attributions to other causes (Branscombe et al., 1999). Along these lines, racial discrimination specifically may constitute an added form of stress contributing to mental health problems among Black Americans. These contrasting models highlight the need for research differentiating between the effects of discrimination attributed to racial versus nonracial causes.

Additional research has examined the role that racial group identification may have in moderating the influence of discrimination on mental health. For example, the rejection- identification model (RIM; Branscombe et al., 1999) suggests that stronger in-group identification in response to discrimination may mitigate the negative implications of these experiences on mental health. A study conducted among Black Americans found that greater racial group identification was associated with better self-esteem and also lessened the impact of discrimination on poor mental health (Branscombe et al., 1999). Similarly, another study found that greater centrality of race to self-definition had a protective effect and also buffered the effect of discrimination on psychological distress (Sellers, Caldwell, Schmeelk-Cone, \& Zimmerman, 2003). Previous studies conducted on other minority populations have also found evidence for the RIM in marginalized communities (Chae \& Yoshikawa, 2008; Romero \& Roberts, 2003; Schmitt, Branscombe, Kobrynowicz, \& Owen, 2002), suggesting that greater in-group identification may serve as a buffer against minority stress.

\section{The Present Study}

Together, these studies suggest that research examining the relationship between discrimination and mental health among Black Americans should distinguish between discrimination attributed to racial versus nonracial causes, which may have different associations with mental health. Research should also incorporate the potential moderating role of racial group identification. However, few studies have examined whether associations between mental health and racial discrimination may be different from associations with other forms of discrimination. Other studies that have examined the influence of discrimination on mental health outcomes among Black Americans have focused exclusively on racial discrimination or have not explicitly examined variations by attribution. In addition, only a handful of studies have examined whether racial group identification may serve as a buffer. Prior studies that have examined these associations have also been limited by the use of nonrepresentative or convenience samples, and findings may not be generalizable to the Black American population.

To address these gaps in knowledge, this study used nationally representative data from the National Survey of American Life (NSAL) to examine serious psychological distress (SPD) in relation to self-reported experiences of discrimination attributed to race versus nonracial causes. We also examined whether racial group identification moderated the impact of racial and nonracial discrimination. Specifically, we hypothesized that: (a) greater self-reported experiences of racial discrimination and nonracial discrimination would both be associated with higher risk of SPD, (b) higher levels of racial group identification would be associated with lower risk of SPD, and (c) racial group identification would buffer the negative influence of discrimination attributed specifically to race.

\section{Method}

\section{Study Procedure and Sample}

The procedures and protocols of the NSAL have been previously documented (Heeringa et al., 2004; Jackson, Neighbors, Nesse, Trierweiler, \& Torres, 2004; Jackson, Torres, et al., 2004). Briefly, the NSAL recruited a national household 
probability sample of 5,191 Black Americans, including 3,570 African Americans and 1,621 Caribbean Black people, between February 2001 and June 2003. In the core sampling component of the NSAL, there were 64 primary sampling units (PSUs), including 21 self-representing metropolitan statistical areas (MSAs) based on overall size and the size of the African American population in those areas, and 43 MSA and non-MSA PSUs from strata that were sampled using a modified probability sampling method. Four hundred fifty-six secondary sampling units defined as area segments were selected using probabilities proportionate to the number of 1990 Census African American households. The NSAL Caribbean Supplement was based on an oversampling of housing units in geographic areas with high densities of people of Caribbean origin. In this component of the sampling procedure, there were eight PSUs, including five PSUs that were already included in the core sample, from which 86 area segments were selected from Census block groups with at least $10 \%$ Caribbean Black density. Households were enumerated and screened, and one eligible participant was selected. Weighting corrections were constructed to take into account the complex sampling design characteristics of the NSAL. Final weighted response rates were $70.7 \%$ and $77.7 \%$ for African American and Caribbean Black respondents, respectively.

Participants were interviewed face-to-face in English by racially concordant trained lay interviewers (mean duration: $2 \mathrm{hr} 20$ min for African Americans; 2 hr 43 min for Caribbean Black people) and were compensated $\$ 50$. All study procedures were approved by the Institutional Review Board of the University of Michigan.

\section{Measures}

Discrimination and attribution. Discrimination was measured as the sum of 10 items developed by Williams, Yu, Jackson, and Anderson (1997) designed to assess interpersonal forms of routine experiences of discrimination: being treated with less courtesy or less respect; receiving poorer service; being perceived as less smart, dishonest, or not as good as others; and being feared, insulted, harassed, and followed in stores. Each item had response values of 0 (never), 1 (less than once a year), 2 (a few times a year), 3 (a few times a month), 4 (at least once a week), and 5 (almost every day). There was a single item at the end of the scale asked only to participants reporting any discrimination assessing the primary reason for such experiences (e.g., race, ethnicity, skin color, gender, sexual orientation, income, age, height, weight), resulting in mutually exclusive categories: (a) none, (b) discrimination with a primary racial attribution (an attribution of race, skin color, or ethnicity), and (c) discrimination with a primary nonracial attribution (an attribution to any other cause).

We further divided participants reporting any discrimination into a priori levels of low (1-10), moderate (11-20), and high (21 or more) intervals that correspond to the mean sum of the first three response choices for individual items. Accordingly, low refers to an average of experiencing each of the 10 forms of discrimination less than once a year (or less), moderate corresponds with an average on each item up to a few times a year, and high refers to an average of more than a few times a year on each item. In order for us to examine the influence of discrimination with or without a primary attribution of race concurrently, we created seven categories: 1 (none), 2 (low nonracial discrimination), 3 (moderate nonracial discrimination), 4 (high nonracial discrimination), 5 (low racial discrimination), 6 (moderate racial discrimination), and 7 (high racial discrimination).

Racial group identification. Racial group identification was measured using a single item assessing how closely the respondents felt in their feelings and ideas to other members of their racial group. Possible responses were not close at all, not too close, fairly close, and very close. In the present study, we classified participants as having low (not close at all or not close), moderate (fairly close), or high (very close) levels of racial group identification.

This item was adapted from the Race Attitudes module of the General Social Survey (GSS), administered biennially from 1996 to 2006. Supporting the use of this item as a measure of racial group identification, we conducted descriptive analyses using GSS data that indicated that Black respondents consistently reported higher levels of closeness to Black people compared with White respondents for all years it was administered.

Serious psychological distress. Psychological distress was assessed using the $\mathrm{K} 6$, a six-item scale designed to measure nonspecific psychological distress in the past 30 days, including symptoms of depression and anxiety (Kessler et al., 2002). Item values ranged from 0 (none of the time) to 4 (all of the time), and summed scores ranged from 0 to $24(\alpha=.80)$. In the present study, we used the cut point of 13 or more to classify participants as having serious psychological distress (SPD; Kessler, Barker, et al., 2003). This cut point requires the participant to endorse experiencing at least one of the symptoms, most of the time (a value of 3 ), to be classified as having SPD and was found to be the optimal threshold in equalizing false positives and false negatives in predicting clinically relevant psychiatric disorders. Previous studies have found evidence for the reliability and validity of the K6 (Kessler et al., 2002; Kessler, Barker, et al., 2003).

Demographic characteristics. We examined several demographic characteristics in our analyses, including selfreported measures of ethnicity (African American or Caribbean Black); gender (men or women); age; ratio of household income to the poverty line, taking into account the number of adults and children (poor, $<100 \%$; near poor, 100\%-199\%; nonpoor with percentage of the poverty line of $200 \%-399 \%$; and nonpoor with percentage of the poverty line of $\geq 400 \%$; National Center for Health Statistics, 1998; U.S. Census Bureau, 2006); years of education ( $<12$ years, 12 years, 13-15 years, 16 years, or more); employment status (employed, unemployed, or out of labor force); and region of residence (northeast, north central, south, or west). We also examined social desirability bias measured as the mean of 10 items endorsed as 1 (true) or 0 (false), which were designed to measure personality factors that may influence responses to sensitive questions (Marlowe \& Crowne, 1961). 


\section{Missing Data}

Missing data were handled using three procedures: (a) NSAL investigators used hot-deck imputation to impute missing values for poverty ratio; (b) for 121 participants who were missing data on at most $20 \%$ of items assessing discrimination (one or two items), we used the mean of remaining items with complete data to substitute for missing values (Roth, Switzer, \& Switzer, 1999); and (c) in multivariable analyses, we used multiple imputation for remaining missing values on all variables using a Markov chain Monte Carlo (MCMC) method to generate five imputations, assuming an arbitrary missing data pattern (Schafer, 1997; Schafer \& Graham, 2002). Imputed values were not rounded but were truncated to fit the bounds of possible values (Allison, 2000; Horton, Lipsitz, \& Parzen, 2003). Multiple imputation is designed to appropriately handle the uncertainty inherent in missing values and has been shown to result in valid statistical inferences (Rubin, 1987).

\section{Data Analysis}

Descriptive analyses were conducted to examine the distribution of sociodemographic characteristics in the total sample and by SPD. We then conducted multivariable weighted logistic regression analyses predicting serious psychological distress, examining the main effects of racial discrimination and nonracial discrimination. We added racial group identification to this model and then its interaction with discrimination.

All analyses were weighted and took into account complex survey design characteristics using SAS-callable SUDAAN. The PROC RLOGIST procedure and the MI_COUNT option were used to obtain summary parameter estimates from multivariable logistic regression analyses.

\section{Results}

\section{Descriptive Results}

Descriptive analyses revealed that most participants reported experiencing some form of discrimination $(89.0 \%)$, and that, of those, a majority made a primary attribution of racial discrimination $(63.5 \%)$. In addition, more than half of participants reported high levels of racial group identification $(52.8 \%)$.

In our study, $4.7 \%$ of participants met criteria for SPD. We observed that those reporting higher levels of both racial and nonracial discrimination were more likely to meet criteria for SPD $\left(\chi^{2}=96.48,6 d f, p<.001\right)$. We also found a significant association between racial group identification and SPD, with participants reporting low levels of racial group identification being more likely to have SPD, and those reporting high levels of racial group identification being less likely to meet criteria for SPD $\left(\chi^{2}=6.78,2 d f, p<.05\right)$. Additional sociodemographic characteristics of the sample are presented in Table 1.

\section{Logistic Regressions Predicting SPD}

Results from weighted logistic regression analyses predicting SPD are reported in Table 2. In our unadjusted bivariate model (Model 1), we found that participants who reported high levels of nonracial discrimination had more than 12 times the odds of meeting criteria for SPD compared with those who reported no discrimination (odds ratio $[\mathrm{OR}]=12.02 ; 95 \%$ confidence interval $[C I]=4.66,31.03)$. In addition, participants who reported moderate $(\mathrm{OR}=3.37 ; 95 \% \mathrm{CI}=1.33,8.56)$ or high $(\mathrm{OR}=$ $10.90 ; 95 \% \mathrm{CI}=4.37,27.18$ ) levels of discrimination with a primary racial attribution had significantly higher odds of meeting criteria for SPD compared with those who reported no discrimination. Controlling for sociodemographic characteristics resulted in substantively similar conclusions, with high levels of nonracial and both moderate and high levels of racially attributed discrimination being associated with significantly higher odds of SPD (Model 2). Furthermore, participants who indicated main attributions of race had somewhat higher odds of SPD compared with those who made primary nonracial attributions for each level (low: $\mathrm{OR}=2.54$ vs. $\mathrm{OR}=1.40$; moderate: $\mathrm{OR}=5.85$ vs. $\mathrm{OR}=2.64$; high: $\mathrm{OR}=17.07$ vs. $\mathrm{OR}=$ 13.17).

We then added racial group identification to the model (Model 3). Although we found that high racial group identification was associated with somewhat lower odds of SPD compared with those with low levels of racial group identification $(\mathrm{OR}=0.72 ; 95 \% \mathrm{CI}=0.40,1.30)$, this association was not statistically significant.

Confidence intervals were wide because of the low prevalence of SPD and from taking into account sampling design effects (i.e., unequal weighting, stratification, and clustering). However, high levels of nonracial discrimination and moderate and high levels of racial discrimination remained statistically significant predictors of SPD.

\section{Interactions Between Racial Group Identification and Discrimination}

We examined whether racial group identification moderated the influence of discrimination on psychological distress by adding the corresponding interaction term to the model. Results are summarized in Table 3. We did not find any statistically significant interactions between moderate levels of racial group identification and discrimination. We did, however, find significant interactions between high levels of racial group identification and moderate levels of nonracial $(t=-2.37, p<.05)$ and racial discrimination $(t=-2.49, p<.05)$.

We present predicted probabilities of SPD among participants with low and high racial group identification by level and type of discrimination in Figure 1, setting all other variables to their mean to illustrate relationships for the average participant. Among those with high levels of racial group identification, we found that predicted probabilities of SPD for moderate levels of both nonracial and racial discrimination were lower compared with those with low levels of racial group identification. The magnitudes of the buffering effects of high racial group identification on moderate levels of both nonracial and racial discrimination in predicting SPD were substantively similar.

\section{Discussion}

Findings from the present study provide further evidence for the negative influence of discrimination on psychological 
Table 1. Frequency and Weighted Percent of Sociodemographic Characteristics Among Black Americans $(N=5,191)$ in the National Survey of American Life (NSAL, 2001-2003)

\begin{tabular}{|c|c|c|c|c|}
\hline & Weighted $n(\%)^{\mathrm{a}}$ & \multicolumn{2}{|c|}{ Serious psychological distress } & $\frac{\text { No SPD vs. SPD }}{\text { Chi-square }(d f)}$ \\
\hline \multicolumn{5}{|l|}{ Serious psychological distress } \\
\hline SPD & $205(4.7)$ & & & \\
\hline \multicolumn{5}{|l|}{ Discrimination/unfair treatment } \\
\hline None & $528(9.7)$ & $9.8(98.8)$ & $2.5(1.2)$ & \\
\hline Nonracial attribution: high & $147(3.3)$ & $3.0(85.6)$ & $10.2(14.4)$ & \\
\hline Racial attribution: low & $792(14.6)$ & $14.8(97.3)$ & $8.3(2.7)$ & \\
\hline Racial attribution: moderate & $1,486(29.6)$ & $29.9(95.4)$ & $28.9(4.6)$ & \\
\hline Racial attribution: high & $597(13.1)$ & $11.8(86.5)$ & $37.2(13.5)$ & $96.48(6)^{* * *}$ \\
\hline \multicolumn{5}{|l|}{ Racial group identification } \\
\hline Low & $519(9.3)$ & $9.0(91.6)$ & $16.6(8.4)$ & \\
\hline Caribbean Black people & $1,621(7.0)$ & $7.1(95.4)$ & $6.9(4.6)$ & $0.01(1)$ \\
\hline \multicolumn{5}{|l|}{ Gender } \\
\hline Men & $1,914(44.5)$ & $45.3(97.1)$ & $27.2(2.9)$ & \\
\hline Women & $3,277(55.5)$ & $54.7(93.8)$ & $72.8(6.2)$ & $17.93(1)^{* * *}$ \\
\hline \multicolumn{5}{|l|}{ Age } \\
\hline$<25$ years & $733(16.4)$ & $16.7(94.8)$ & $18.4(5.2)$ & \\
\hline $25-39$ years & $1,745(30.9)$ & $31.4(95.6)$ & $29.1(4.4)$ & \\
\hline $40-64$ years & $2,109(41.2)$ & $40.7(94.6)$ & $47.1(5.4)$ & \\
\hline 65 years or more & $604(11.5)$ & $11.3(97.7)$ & $5.4(2.3)$ & $13.94(3)^{* *}$ \\
\hline \multicolumn{5}{|l|}{ Poverty level } \\
\hline Poor $(<100 \%)$ & $1,182(23.2)$ & $22.2(90.9)$ & $45.3(9.1)$ & \\
\hline Near poor $(100 \%-199 \%)$ & $1,305(23.8)$ & $23.3(93.6)$ & $32.1(6.4)$ & \\
\hline Nonpoor $(200 \%-399 \%)$ & $1,644(32.3)$ & $32.9(97.4)$ & $17.6(2.6)$ & \\
\hline Unemployed & $524(10.0)$ & $9.7(91.1)$ & $19.4(9.0)$ & \\
\hline Out of labor force & $1,140(22.6)$ & $21.7(93.2)$ & $32.2(6.8)$ & $19.02(2)^{* * *}$ \\
\hline \multicolumn{5}{|l|}{ Region } \\
\hline Northeast & $1,546(18.5)$ & $18.7(94.5)$ & $21.9(5.5)$ & \\
\hline North central & $607(17.8)$ & $16.2(93.1)$ & $24.4(6.9)$ & \\
\hline South & $2,786(54.4)$ & $55.2(95.9)$ & $47.6(4.1)$ & \\
\hline West & $252(9.4)$ & $9.9(97.0)$ & $6.2(3.0)$ & $6.11(3)$ \\
\hline
\end{tabular}

Note. SPD $=$ serious psychological distress.

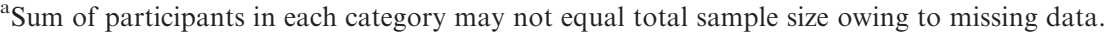

${ }^{*} p<.05 .{ }^{* *} p<.01 . * * * p<.001$.

distress among Black Americans and extend prior research by examining differences between discrimination with a primary attribution of race versus other causes. In addition, by investigating the role of racial group identification and whether it moderates the influence of discrimination on psychological distress, we contribute to the extant literature in this area. An additional strength of our study is the use of nationally representative data. Results indicated that Black Americans who reported high levels of discrimination with a primary nonracial attribution, and those who reported moderate and high levels of racially attributed discrimination, had significantly higher odds of SPD compared with those reporting no discrimination. Moreover, high levels of racial group identification buffered the negative mental health effects of moderate levels of 
Table 2. Logistic Regressions Predicting Serious Psychological Distress Among Black Americans: National Survey of American Life $(N=5,191), 2001-2003$

\begin{tabular}{|c|c|c|c|}
\hline & Model 1: OR $(95 \% \mathrm{CI})$ & Model 2: OR $(95 \% \mathrm{CI})$ & Model 3: OR $(95 \% \mathrm{CI})$ \\
\hline \multicolumn{4}{|l|}{ Nonracial unfair treatment } \\
\hline Low vs. none & $1.10(0.45,2.70)$ & $1.40(0.55,3.56)$ & $1.38(0.54,3.53)$ \\
\hline High vs. none & $12.02(4.66,31.03)$ & $13.17(4.90,35.43)$ & $12.98(4.80,35.14)$ \\
\hline \multicolumn{4}{|l|}{ Racial discrimination } \\
\hline Low vs. none & $1.06(0.37,3.04)$ & $2.54(0.84,7.62)$ & $2.50(0.84,7.48)$ \\
\hline \multicolumn{4}{|l|}{ Racial group identification } \\
\hline Moderate vs. low & & & $0.90(0.46,1.77)$ \\
\hline High vs. low & & & $0.72(0.40,1.30)$ \\
\hline Ethnicity: Caribbean vs. African American & & $1.17(0.57,2.38)$ & $1.16(0.57,2.36)$ \\
\hline Gender: women vs. men & & $2.37(1.31,4.28)$ & $2.32(1.28,4.20)$ \\
\hline Age & & $1.00(0.99,1.01)$ & $1.00(0.99,1.01)$ \\
\hline \multicolumn{4}{|l|}{ Poverty level } \\
\hline 12 years vs. $<12$ years & & $0.73(0.46,1.16)$ & $0.73(0.45,1.19)$ \\
\hline $13-15$ years vs. $<12$ years & & $0.49(0.26,0.93)$ & $0.50(0.26,0.95)$ \\
\hline $16+$ years vs. $<12$ years & & $0.36(0.14,0.93)$ & $0.37(0.14,0.96)$ \\
\hline \multicolumn{4}{|l|}{ Work status } \\
\hline Unemployed vs. employed & & $1.50(0.86,2.63)$ & $1.50(0.85,2.63)$ \\
\hline Out of labor force vs. employed & & $1.67(0.98,2.84)$ & $1.66(0.97,2.82)$ \\
\hline \multicolumn{4}{|l|}{ Region } \\
\hline Northeast vs. South & & $1.49(0.94,2.38)$ & $1.44(0.89,2.34)$ \\
\hline North Central vs. South & & $1.46(0.91,2.34)$ & $1.42(0.89,2.28)$ \\
\hline West vs. South & & $0.71(0.26,1.97)$ & $0.70(0.26,1.91)$ \\
\hline Social desirability & & $2.19(0.89,5.38)$ & $2.23(0.87,5.69)$ \\
\hline
\end{tabular}

Table 3. Interaction Terms in Logistic Regression Models Predicting Serious Psychological Distress Among Black Americans: National Survey of American Life ( $N=5,191)$, 2001-2003

\begin{tabular}{lc}
\hline & $t$-statistic \\
\hline Moderate racial group identification & \\
$\quad$ Nonracial attribution & .62 \\
$\quad$ Low $\times$ moderate identification & -1.18 \\
$\quad$ Moderate $\times$ moderate group identification & -1.62 \\
$\quad$ High $\times$ moderate identification & \\
Racial attribution & -.59 \\
$\quad$ Low $\times$ moderate identification & -1.59 \\
$\quad$ Moderate $\times$ moderate identification & -1.43 \\
$\quad$ High $\times$ moderate identification & \\
High racial group identification & -.31 \\
Nonracial attribution & $-2.37^{*}$ \\
$\quad$ Low $\times$ high identification & -1.57 \\
$\quad$ Moderate $\times$ high group identification & \\
High $\times$ high identification & -1.66 \\
Racial attribution & $-2.49^{*}$ \\
$\quad$ Low $\times$ high identification & -1.81 \\
$\quad$ Moderate $\times$ high identification & \\
High $\times$ high identification &
\end{tabular}

$* p<.05$. both nonracial and racial discrimination. Our study highlights the negative mental health consequences of discrimination among Black Americans. In addition, our study suggests that racial group identification may mitigate the negative effects of moderate levels of discrimination on psychological distress, regardless of attribution.

Although bivariate analyses revealed a significant association between racial group identification and SPD, we did not find evidence for a main protective effect of racial group identification after controlling for sociodemographic variables. However, our findings do suggest that high racial group identification may serve as a buffer. This latter finding is consistent with the rejection-identification model (Branscombe et al., 1999), which suggests that greater racial group identification following the experience of racial discrimination may alleviate its effects on mental health. Contrary to what was hypothesized, high racial group identification buffered not only moderate levels of racial discrimination, but also other forms of discrimination to a similar extent. This finding suggests that close racial group identification may protect against various forms of stress, including those that may be nonracially attributed. However, racial group identification only buffered moderate levels of discrimination, suggesting that extreme levels of these stressors may have 


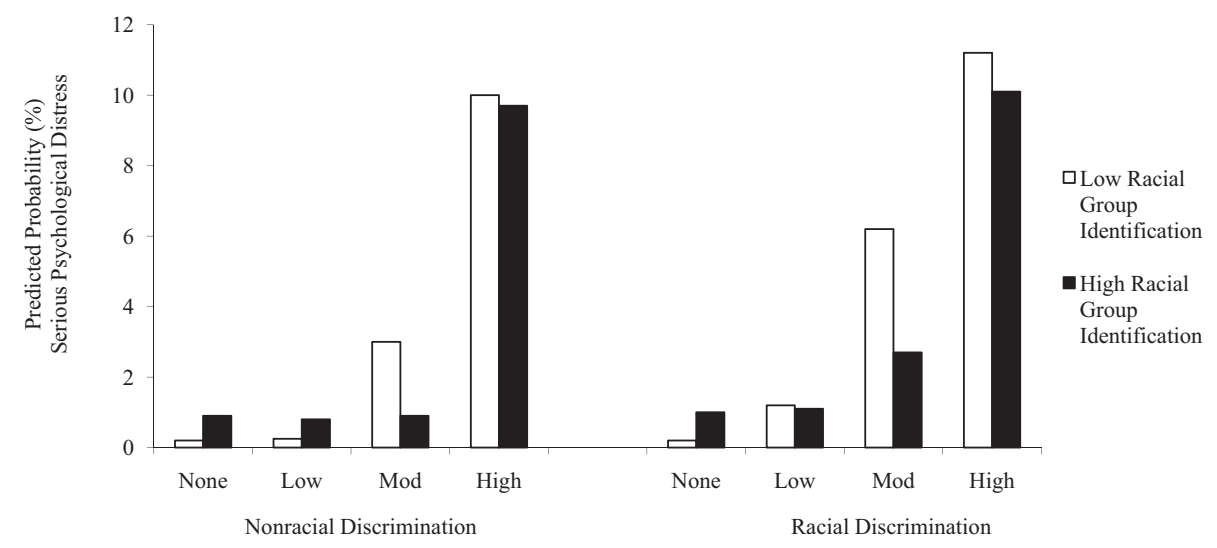

Figure 1. Predicted probabilities of serious psychological distress among Black Americans: National Survey of American Life ( $N=5,191), 2001-2003$.

negative consequences for mental health despite the presence of potential psychological buffers.

Our findings are concordant with theories suggesting that interpreting negative experiences as discriminatory may not necessarily be protective, particularly among members of disadvantaged social groups (Schmitt \& Branscombe, 2002). We found that discrimination that was attributed to race was associated with somewhat higher odds of SPD compared with discrimination attributed to nonracial causes after taking into account sociodemographic characteristics. This result, however, does not necessarily conflict with other theories that posit that attributions to group-based discrimination may have protective properties (Crocker \& Major, 1989; Major et al., 2003). A caveat to our findings is that we had combined nonracial forms of discrimination (e.g., based on gender or sexual orientation) with other experiences that may have been attributed to more individual characteristics. Despite this limitation, our findings draw attention to the heterogeneity of types of discrimination experienced by Black people and their salience for psychological distress in this population. Specifically, our study suggests that experiences of discrimination, including those primarily attributed to race as well as other causes, have negative implications for mental health among Black people (Broman et al., 2000; Gee et al., 2006; Jackson et al., 1996; Klonoff et al.,1999; Schulz et al., 2006). Furthermore, racial discrimination specifically may constitute an added source of psychological burden contributing to poor mental health among Black Americans.

Our results are also consistent with previous research on African Americans, suggesting that racial centrality, defined as the degree to which members define themselves by their race, may have direct protective effects on mental health as well as buffer the influence of discrimination (Sellers \& Shelton, 2003; Sellers et al., 2003). However, other research has suggested that greater identification with a devalued minority group may be associated with worse mental health outcomes in other minority populations (Chae \& Yoshikawa, 2008; Zea, Reisen, \& Poppen, 1999). In light of the limitations inherent in our use of a single item to measure racial group identification and given plausible alternative findings, additional research on minority group identification is warranted among Black Americans. Future research may also examine additional dimensions of racial or ethnic identity, including personal group evaluation, membership appraisal, or group participation as potential moderators of the influence of discrimination (Chae \& Yoshikawa, 2008; Sellers \& Shelton, 2003; Sellers et al., 2003).

In addition, the cross-sectional and self-reported nature of the data also limits inferences regarding causality and the causal direction of our observed associations. For example, it is possible that participants with SPD were more likely to perceive and report experiencing discrimination. Nevertheless, our interpretation of findings is consistent with those of prior studies, including those of a longitudinal study that reported a positive association between changes in discrimination and depression (Schulz et al., 2006).

Considering the strengths and limitations of our study, our findings offer several implications for research examining psychological distress among Black Americans and also suggest the need for policies to confront issues of discrimination to protect against poor mental health outcomes in this population. In addition to structural and institutional forms of discrimination, our study indicates that we should be concerned with routine forms of discrimination that, though not illegal per se, have deleterious effects on the psychological well-being of Black Americans. Our findings also suggest that community- or individual-level interventions designed to promote racial group identification may be effective in ameliorating the negative mental health consequences of experiencing discrimination (Dana, 2002; Whaley \& McQueen, 2010). Our study draws attention to these risk and protective factors for psychological distress among Black Americans.

Keywords: Black Americans; racial discrimination; nonracial discrimination; racial group identification; psychological distress; National Survey of American Life

\section{References}

Allison, P. (2000). Multiple imputation for missing data: A cautionary tale. Sociological Methods and Research, 28, 301-309.

Bhui, K., Stansfeld, S., McKenzie, K., Karlsen, S., Nazroo, J., \& Weich, S. (2005). Racial/ethnic discrimination and common mental disorders among workers: Findings from the EMPIRIC study of ethnic 
minority groups in the United Kingdom. American Journal of Public Health, 95, 496-501.

Blazer, D. G., Kessler, R. C., McGonagle, K. A., \& Swartz, M. S. (2004). The prevalence and distribution of major depression in a national community sample: The National Comorbidity Survey. American Journal of Psychiatry, 151, 979-986.

Branscombe, N. R., Schmitt, M. T., \& Harvey, R. D. (1999). Perceiving pervasive discrimination among African Americans: Implications for group identification and well-being. Journal of Personality and Social Psychology, 77, 135-149.

Breslau, J., Kendler, K. S., Su, M., Gaxiola-Aguilar, S., \& Kessler, R. C. (2005). Lifetime risk and persistence of psychiatric disorders across ethnic groups in the United States. Psychological Medicine, 35, $317-$ 327.

Broman, C. L., Mavaddat, R., \& Hsu, S. (2000). The experience and consequences of perceived racial discrimination: A study of African Americans. The Journal of Black Psychology, 26, 165-180.

Chae, D. H., \& Yoshikawa, H. (2008). Perceived group devaluation, depression, and HIV risk behavior among Asian gay men. Health Psychology, 27, 140-148.

Clark, R., Anderson, N. B., Clark, V. R., \& Williams, D. R. (1999). Racism as a stressor for African Americans: A biopsychosocial model. American Psychologist, 54, 805-816.

Crocker, J., \& Major, B. (1989). Social stigma and self-esteem: The selfprotective properties of stigma. Psychological Review, 96, 608-630.

Dana, R. H. (2002). Mental health services for African Americans: A cultural/racial perspective. Cultural Diversity and Ethnic Minority Psychology, 8, 3-18.

Díaz, R. M., Ayala, G., Bein, E., Henne, J., \& Marin, B. V. (2001). The impact of homophobia, poverty, and racism on the mental health of gay and bisexual Latino men: Findings from 3 U.S. cities. American Journal of Public Health, 91, 927-932.

Finch, B. K., Kolody, B., \& Vega, W. A. (2000). Perceived discrimination and depression among Mexican-origin adults in California. Journal of Health and Social Behavior, 41, 295-313.

Gee, G. C., Ryan, A., Laflamme, D. J., \& Holt, J. (2006). Self-reported discrimination and mental health status among African descendents, Mexican Americans, and other Latinos in the New Hampshire REACH 2010 Initiative: The added dimension of immigration. American Journal of Public Health, 96, 1821-1828.

Gee, G. C., Spencer, M., Chen, J., Yip, T., \& Takeuchi, D. T. (2007). The association between self-reported racial discrimination and 12month DSM-IV mental disorders among Asian Americans nationwide. Social Science and Medicine, 64, 1984-1996.

Heeringa, S. G., Wagner, J., Torres, M., Duan, N., Adams, T., \& Berglund, P. (2004). Sample designs and sampling methods for the Collaborative Psychiatric Epidemiology Studies (CPES). International Journal of Methods in Psychiatric Research, 13, 221-240.

Horton, N. J., Lipsitz, S. R., \& Parzen, M. (2003). A potential for bias when rounding in multiple imputation. American Statistician, 57, 220-232.

Jackson, J. S., Brown, T. N., Williams, D. R., Torres, M., Sellers, S. L., \& Brown, K. (1996). Racism and the physical and mental health status of African Americans: A thirteen year national panel study. Ethnicity \& Disease, 6, 132-147.

Jackson, J. S., Neighbors, H. W., Nesse, R. M., Trierweiler, S. J., \& Torres, M. (2004). Methodological innovations in the National Survey of American Life. International Journal of Methods in Psychiatric Research, 13, 289-298.

Jackson, J. S., Torres, M., Caldwell, C. H., Neighbors, H. W., Nesse, R. M., Taylor, R. J., . . . Williams, D. R. (2004). The National Survey of American Life: A study of racial, ethnic and cultural influences on mental disorders and mental health. International Journal of Methods in Psychiatric Research, 13, 196-207.
Jargowsky, P. A. (1997). Poverty and place: Ghettos, barrios, and the American city. New York, NY: Russell Sage Foundation.

Kessler, R. C., Andres, G., Colpe, L. J., Hiripi, E., Mroczek, D. K., Normand, S. T., . . Z Zaslavsky, A. M. (2002). Short screening scales to monitor population prevalences and trends in non-specific psychological distress. Psychological Medicine, 32, 959-976.

Kessler, R. C., Barker, P. R., Colpe, L. J., Epstein, J. F., Gfroerer, J. C., Hiripi, E., . . Z Zaslavsky, A. M. (2003). Screening for serious mental illness in the general population. Archives of General Psychiatry, 60, 184-189.

Kessler, R. C., Berglund, P., Demler, O., Jin, R., Koretz, D., Merikangas, K. R., . . . Wang, P. S. (2003). The epidemiology of major depressive disorder: Results from the National Cormorbidity Survey Replication (NCS-R). Journal of the American Medical Association, 289, 3095-3105.

Kessler, R. C., McGonagle, K. A., Zhao, S., Nelson, C. B., Hughes, M., Eshelman, S., . . Kendler, K. S. (1994). Lifetime and 12-month prevalence of DSM-III-R psychiatric disorders in the United States: Results from the National Comorbidity Study. Archives of General Psychiatry, 51, 8-19.

Klonoff, E. A., Landrine, H., \& Ullman, J. B. (1999). Racial discrimination and psychiatric symptoms among Blacks. Cultural Diversity and Ethnic Minority Psychology, 5, 329-339.

Krieger, N. (2000). Discrimination and health. In L. Berkman \& I. Kawachi (Eds.), Social epidemiology (pp. 36-75). New York, NY: Oxford University Press.

Major, B., Kaiser, C. R., \& McCoy, S. K. (2003). It's not my fault: When and why attributions to prejudice protect self-esteem. Personality and Social Psychology Bulletin, 29, 772-781.

Marlowe, D., \& Crowne, D. P. (1961). Social desirability and response to perceived situational demands. Journal of Consulting Psychology, $25,109-115$.

Meyer, I. H. (2003). Prejudice as stress: Conceptual and measurement problems. American Journal of Public Health, 93, 262-265.

National Center for Health Statistics. (1998). Health, United States, 1998 with socioeconomic and health chartbook. Hyattsville, MD: National Center for Health Statistics.

Neighbors, H. W., Jackson, J. S., Broman, C., \& Thompson, E. (1996). Racism and the mental health of African Americans: The role of self and system blame. Ethnicity and Disease, 6, 167-175.

Romero, A. J., \& Roberts, R. E. (2003). The impact of multiple dimensions of ethnic identity on discrimination and adolescents' self-esteem. Journal of Applied Social Psychology, 33, 2288-2305.

Roth, P. L., Switzer, F. S., \& Switzer, D. M. (1999). Missing data in multiple item scales: A Monte Carlo analysis of missing data techniques. Organizational Research Methods, 2, 211-232.

Rubin, D. B. (1987). Multiple imputation for nonresponse in surveys. New York, NY: John Wiley and Sons.

Schafer, J. L. (1997). Analysis of incomplete multivariate data. New York, NY: Chapman and Hall.

Schafer, J. L., \& Graham, J. W. (2002). Missing data: Our view of the state of the art. Psychological Methods, 7, 147-177.

Schmitt, M. T., \& Branscombe, N. R. (2002). The meaning and consequences of perceived discrimination in disadvantaged and privileged social groups. In W. Stroebe \& M. Hewstone (Eds.), European review of social psychology, (Vol. 12, pp. 167-199). Chichester, England: Wiley.

Schmitt, M. T., Branscombe, N. R., Kobrynowicz, D., \& Owen, S. (2002). Perceiving discrimination against one's gender group has different implications for well-being in women and men. Personality and Social Psychology Bulletin, 28, 197-210.

Schmitt, M. T., Branscombe, N. R., \& Postmes, T. (2003). Women's emotional responses to the pervasiveness of gender discrimination. European Journal of Social Psychology, 33, 297-312. 
Schulz, A. J., Gravlee, C. C., Williams, D. R., Israel, B. A., Mentz, G., \& Rowe, Z. (2006). Discrimination, symptoms of depression, and self-rated health among African American women in Detroit: Results from a longitudinal analysis. American Journal of Public Health, 96, $1265-1270$.

Sellers, R. M., Caldwell, C. H., Schmeelk-Cone, K. H., \& Zimmerman, M. A. (2003). Racial identity, racial discrimination, perceived stress, and psychological distress among African American young adults. Journal of Health and Social Behavior, 44, 302-317.

Sellers, R. M., \& Shelton, J. N. (2003). The role of racial identity in perceived racial discrimination. Journal of Personality and Social Psychology, 84, 1079-1092.

Tajfel, H., \& Turner, J. C. (1986). The social identity theory of intergroup behavior. In S. Worchel \& W. G. Austin (Eds.), Psychology of intergroup relations (pp. 7-24). Chicago, IL: Nelson-Hall.

U.S. Census Bureau. (2006). Poverty thresholds 2000. Retrieved from http://www.census.gov/hhes/www/poverty/threshld/thresh00.html.

Weiner, B. (1985). An attributional theory of achievement motivation and emotion. Psychological Review, 92, 548-573.

Whaley, A. L., \& McQueen, J. P. (2010). Evaluating cohort and intervention effects on Black adolescents' ethnic-racial identity: A cognitive-cultural approach. Evaluation and Program Planning, 33, 436-445.

Williams, D. R., \& Collins, C. (2001). Racial residential segregation: A fundamental cause of racial disparities in health. Public Health Reports, 116, 404-416.
Williams, D. R., Gonzalez, H., Neighbors, H., Nesse, R., Abelson, J. M., Sweetman, J., \& Jackson, J. S. (2007). Prevalence and distribution of major depressive disorder in African Americans, Caribbean Blacks, and non-Hispanic Whites: Results from the National Survey of American Life. Archives of General Psychiatry, 64, 305-315.

Williams, D. R., Neighbors, H. W., \& Jackson, J. S. (2003). Racial/ ethnic discrimination and health: Findings from community studies. American Journal of Public Health, 93, 200-208.

Williams, D. R., \& Williams-Morris, R. (2000). Racism and mental health: The African American experience. Ethnicity \& Health, 5, 243268.

Williams, D. R., Yu, Y., Jackson, J. S., \& Anderson, N. B. (1997). Racial differences in physical and mental health: Socioeconomic status, stress, and discrimination. Journal of Health Psychology, 2, 335-351.

Yoshikawa, H., Wilson, P. A., Chae, D. H., \& Cheng, J. (2004). Do family and friendship networks protect against the influence of discrimination on mental health and HIV risk among Asian and Pacific Islander gay men? AIDS Education and Prevention, 16, 84-100.

Zea, M. C., Reisen, C. A., \& Poppen, P. J. (1999). Psychological well-being among Latino lesbians and gay men. Cultural Diversity and Ethnic Minority Psychology, 5, 371-379. 